\title{
Termodinâmica Fundamental para Ciências e Engenharias
}

\author{
por João Paulo M. Ferreira, Universidade Católica Editora, 2003, \\ 292 págs. €22,00. ISBN 972-54-0047-X
}

M A R I A E Gén I A R B ELLO DE A L M E D A M A C E D *

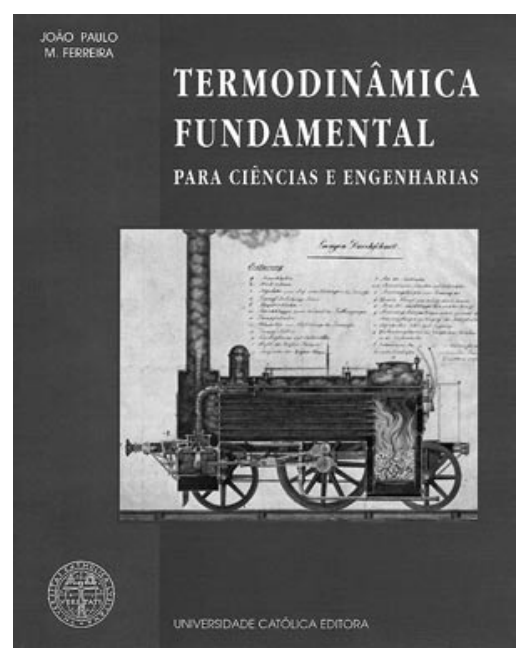

"Termodinâmica Fundamental para Ciências e Engenharias" é um texto de introdução à termodinâmica, escrito em língua portuguesa, com muita qualidade e em que são versados assuntos relevantes neste tema, reconhecidamente fundamental em todas as tecnologias.

O livro, que tem uma índole essencialmente pedagógica, apresenta os conceitos fundamentais e as várias matérias de forma clara, numa linguagem simples, mas sem perder o elevado rigor científico que se impõe, e recorrendo sempre que possível a exemplos, alguns ligados ao quotidiano, o que revela um enorme cuidado com vista a uma melhor compreensão física dos fenómenos.

Apresenta um capítulo inicial em que o autor faz uma breve nota histórica da Termodinâmica, onde se podem encontrar os nomes dos cientistas que ficaram

"Desde há alguns anos, lecciono uma disciplina de Termodinâmica, nível básico, simultaneamente para alunos de engenharia e de ciências biológicas. Os conteúdos programáticos e os métodos didácticos têm assim de se adaptar a diferentes objectivos. (...)

Para primeiro curso parece-me fundamental privilegiar a compreensão física ou visão mecanicista dos fenómenos, sem a qual toda a aprendizagem posterior ficará comprometida. Não obstante a simplicidade houve preocupação em manter o rigor e a correcção formal das análises."

(do prefácio)

ligados aos conceitos base e à evolução da Termodinâmica, com alusão às respectivas contribuições. Constitui, certamente, um factor de incentivo para os estudantes que estão a iniciar os estudos neste tema.

A este capítulo seguem-se os restantes onze, onde são introduzidos os conceitos fundamentais desta ciência, e seguidamente são estudadas as diferentes formas de energia e suas trocas, os Primeiro e Segundo Princípios da Termodinâmica e Entropia. Existem ainda capítulos dedicados ao estudo de equilíbrio de fases, propriedades termodinâmicas para sistemas em equilíbrio, equilíbrio com reacções químicas, Terceira Lei da Termodinâmica, comportamento de gases reais e também balanços em sistemas abertos. Os capítulos são, geralmente, curtos e bastante específicos da matéria aí abordada, com exemplos de aplicação para maior facilidade de aprendizagem. No final de cada um, existe uma lista de problemas propostos para resolução.

De salientar que, como o próprio autor também esclarece no prefácio, este é um texto de introdução à Termodinâmica clássica, não abrangendo todos os assuntos relevantes em diferentes licenciaturas. De facto, na licenciatura em Engenharia Química, por exemplo, este texto poderá ser usado numa fase inicial, devendo ser obrigatoriamente acompanhado por outros livros ou manuais em que as propriedades termodinâmicas e os equilíbrios de fases e reaccionais de misturas sejam contemplados com a profundidade requerida para a formação nesta área.

* Professora Associada c/ Agregação de Termodinâmica Química do Departamento de Engenharia Química, Faculdade de Engenharia da Universidade do Porto 